\title{
Analysis, design and construction of gravity offshore structure; State-of- the-art
}

\author{
Samuel Adakole Okpe ${ }^{1^{*}}$, Joseph Ejelikwu Edeh ${ }^{2}$ \\ ${ }^{I}$ Civil Engineering Department, Near East University, Nicosia, Via Mersin 10, Turkey \\ ${ }^{2}$ Civil Engineering Department, Federal University of Agriculture, Makurdi, Benue State, Nigeria
}

ARTICLE INFO

\section{ARTICLE HISTORY:}

Received: 16 April 2021

Revised: 08 June 2021

Accepted: 15 July 2021

Published: 19 November 2021

\section{KEYWORDS:}

Gravity platform, offshore, condeep, concrete platform

\section{A B S T R A C T}

Offshore platforms are divided into many types which are mainly categorized according to waterdepth in the installation location. However, the design differs for each type to accomplish the target of the operation. But for some case of sea waterdepth and an aggressive environment such as the North Sea, steel ones are not suitable, so the heaviest type called gravity platform having enormous mass is used. This type of platform has its special requirements and procedures for construction and needs special types of construction materials in order to resist the climate factors applied due to the aggressive environment. The paper carefully illustrates how the principal Environmental loads (wind and wave), current forces, loads from ice and loads from earth-quake for earthquake prone zones are deployed to archive the design and construction of offshore concrete gravity platforms. Two design methods of analysis and design of shell structures as well as the Tangent modulus methods of design of offshore concrete gravity platforms are discussed.

\section{INTRODUCTION}

Offshore platforms have many uses including oil exploration and production, navigation, ship loading and unloading, and to support bridges and causeways. Offshore oil production is one of the most visible of these applications and represents a significant challenge to the design engineer. These offshore structures must function safely for design lifetimes of twenty-five years or more and are subject to very harsh marine environments. (Nouban, 2017). Some important design considerations are peak loads created by hurricane wind and waves, fatigue loads generated by waves over the platform lifetime and the motion of the platform. The platforms are sometimes subjected to strong currents which create loads on the mooring system and can induce vortex shedding. (Sadeghi, 2007).

The three main types of offshore concrete structures are as follows (Atkins Process Limited and Olav Olsen, 2003):

- Tower and caisson types with circular caisson cells (Condeep),

- Tower and caisson types with rectangular caisson cells,

- Jarlan wall types (Doris).
Offshore substructures have proved to be highly endurance to the harsh marine conditions, this is due to the strength of the reinforced concrete that can be further reinforced on demand to meet the requirements of several sites (Chakrabarti, 2005). Gravity platforms that are essentially made of reinforced concrete, fixing it rigidly to the sea-bed and giving it more resistance to the sea waves (Sadeghi, 2008; Sadeghi, 2001 and Tianwei, 2010). There are various advantages and reason to use gravity platforms such as:

- Built on an onshore site,

- Concrete structures, not relying on piles require great mass to stay put in the face of sea storms even severe storms,

- Because the concrete tanks are so massive, they can carry heavy oil production platforms up top,

- Ease of transportation,

- Concrete itself performs well under low temperature conditions,

- Conveniently installed by means of submerging,

- The simplicity of installation methods (Chandrasekaran, 2015). 
Some consideration shall be given before the use of gravity platform as there are potential disadvantages in their use where:

- Requires significantly high soil standards,

- Additional labor need for the pre-construction phases,

- Prolonging the production as it commences after the construction competition. (Chandrasekaran, 2015).

\section{MATERIALS AND METHODOLOGY}

\subsection{Material}

In this section material selection criteria and requirement for the design of the gravity platform has been outlined.

\subsubsection{Concrete}

Concrete mixture design criteria were as follows:

- Compressive strength of $65 \mathrm{MPa}$ (9430 psi).

- Maximum water-cementitious materials ratio of $\mathrm{w} / \mathrm{c}=0.4$

- Cementitious material content between 360 and 450 $\mathrm{kg} / \mathrm{m}$,

- High slump of $240 \mathrm{~mm}$ (9.5 in.) to deal with congested reinforcement.

\subsubsection{Solid ballast}

Solid ballast with a specified density of $3500 \mathrm{~kg} / \mathrm{m}^{3}$ $\left(220 \mathrm{lb} / \mathrm{ft}^{3}\right)$ is required as a slurry mixture comprising iron ore, fly ash, cement, and high-range water-reducing admixtures. All solid ballast installation can be performed at the deep-water site using concrete pumps.

\subsubsection{Reinforcement}

Grade 500W weldable deformed bars per the requirements of CSA A23.1-09 can be used for reinforcement. T-headed bars can be provided to improve anchorage, eliminate hooks, and reduce congestion. The minimum concrete cover for steel reinforcement (including stirrups) is $50 \mathrm{~mm}$ ( $2 \mathrm{in}$.) in the splash zone and $40 \mathrm{~mm}$ (1.6 in.) in the submerged zone.

\subsection{Design considerations}

During the design phase of the gravity platform, environmental and wind loads, current forces, loads from ice and from earthquakes to name a few shall all be considered, in this section we will detail the design considerations.

\subsubsection{Environmental loads}

Waves and winds are the two principal environmental loads considered in the design of offshore gravity platforms. The design environmental loads are normally based on environmental conditions which have a recurrence period of 100 years, and the design life time of offshore structures is about 20 - 30 years. There are two methods of evaluating the wave loads on a fixed offshore structure, which can be described as:

- Design wave method: This is a static method. The load value is derived from the passage of a single regular wave of given height and length past the structure. Currently a 20 secs limit on wave period is recommended.

- Spectral analysis method: Spectral analysis has frequently been used to predict maximum wave forces responses as an alternate to the deterministic design wave method. This method is very suitable for gravity structures where the initial wave forces dominate.

\subsubsection{Wind loads}

The force exerted by wind on an offshore structure is a function of three basic parameters the wind velocity, the orientation of the structure, and the aerodynamic characteristics of the structure and its members. The wind force exerted on a structure consists of two components, one parallel to the direction of travel of the wind and the other perpendicular to the direction of travel of the wind.

$$
F_{D}=C_{d}^{\frac{1}{2}} p V_{Z}^{2} A \rightarrow \text { (Force parallel to wind) }
$$

This is also called Drag force and this tends to tilt the structure and is responsible for a large percentage of the overturning moment.

$F_{L}=C_{L}^{\frac{1}{2}} p V_{Z}^{2} A \rightarrow($ Force perpendicular to wind, tends to lift the structure)

where:

$C_{d}$ : drag coefficient,

$C_{L}$ : lift coefficient,

$\rho$ : density of the air,

$V_{Z}$ : wind velocity,

$A$ : Area perpendicular to wind velocity.

The wind velocity is not constant because of the shear forces with the earth's surface; it is zero at the surface and increases exponentially to a limiting maximum speed known as the gradient wind. Over water the wind speed at any elevation is represented by the one-seventh power law. 


$$
V_{Z}=V_{\text {ref }}\left(\frac{Z}{R e f}\right)^{1 / 7}
$$

where:

$V_{\text {ref: }}$ the wind speed at a height of $30 \mathrm{ft}$,

$Z$ : desired elevation in $\mathrm{ft}$,

Ref: the reference height (30 ft). should be calculated. The two kinds of wind speeds are normally considered.

- Sustained wind speed, which is defined as the average wind speed during the time interval of one minute,

- Gust wind speed, which is defined as the average wind speed during a time interval of $3 \mathrm{sec}$. The gust factor is that multiplier which must be used on the sustained wind speed to obtain the gust speed, or the fastest - mile velocity. The average gust factor, F10, at the $30 \mathrm{ft}$ elevation is in the range $1.35-1.45$.

Another commonly accepted formula for calculating the wind force is

$$
F=K V^{2} C_{S} A
$$

where:

$$
\begin{aligned}
& F: \text { wind force, } \\
& K: \text { constant, } \\
& V: \text { design wind speed, } \\
& C_{S}: \text { shape coefficient, } \\
& A=\text { projected area, } \\
& K=0.00256\left(\mathrm{lbf}, \mathrm{mile} / \mathrm{hr} \mathrm{ft}^{2}\right) .
\end{aligned}
$$

Typical shape coefficients, for all angles of wind approach could be; Beams Cs $=1.5$ and for the Slides of Buildings $C s=1.5$ whereas Cylindrical Sections $C s=1.0$.

\subsubsection{Current forces}

Two major components of the current are considered: tidal current and wind driven current. It is generally accepted that the wind driven current at the still water surface may be taken as $1 \%$ of the sustained wind speed at $30 \mathrm{ft}(10 \mathrm{~m})$ above the still water level. The current velocity should be added vectorially to the wave particle velocity before computing the drag force. Because drag depends on the square of the horizontal particle velocity, and because the current decreases with slowly with depth, a comparatively small current can increase drag significantly. In design, the maximum wave height is sometimes increased by $3-4 \%$ to account for the current effects and the current per sec is neglected.
The wind effects on all parts of the above water structure

\subsubsection{Loads from ice}

In areas prone to snow, the structure should be designed to resist all static and impact forces from ice. In all locations where the hazard of floating ice may exist, the thickness and strength of the ice, and the velocity with which the ice may strike the structure should be determined. With pack or sheet ice, the mode of failure of the ice should be determined. In some locations, ice may accumulate on the structure and superstructure. Allowance should be made for the effect of this accumulation upon the stability of, and upon the stresses in the structure.

\subsubsection{Loads from earthquakes}

Where the site is in an area with a history of recorded earthquakes, the structure should be designed to resist lateral and vertical forces and overturning moments arising from seismic activities. The information used to establish a design earthquake should be taken from data recorded for previous earthquakes at or near the site, if such data are available. (Otunyo, 2011).

\section{DESIGN METHODS}

Design of offshore gravity structures, is based on limit (semi probabilistic methods). Limit State - A structure or structural member reaches a Limit state of fitness in a condition where it just ceases to fulfill the resistance requirements or other specifications as regards structural performance for which it has been designed.

\subsection{Analysis and design of gravity structures}

Gravity platforms consist mainly of various cylindrical shells of large dimensions. These shells are capped with spherical or conical domes at bottom and top. Further, all these platforms are equipped with concrete or steel skirts in the form of short cylindrical shells, or both as a means of scour protection and of assuming sufficient resistance against horizontal sliding. (Hsai, 1991).

The complexity of the various shell components connected together coupled with the complex actions of the environmental loads and other load combinations renders the analysis and design of such structures difficult. It is important that the walls of concrete shell be properly proportioned to prevent catastrophic collapse against various periods of large hydrostatic pressure exposure. Potential failure modes to be considered are material failure and structural stability. The following software can be used for the structural analysis of offshore gravity structures:

- For structural analysis: SACS, FASTRUDL, MARCS, OSCAR, StruCad or SESAM,

- For the hydrodynamic calculations of barges: Maxsurf, Hydromax and Seamoor, 
- For pile analyses: GRLWEAP, PDA and CAPWAP (Nouban, 2016).

\subsubsection{Tangent modulus methods}

Research has shown that the tangent modulus buckling concept is proper for the prediction of the maximum strength of many types of columns i.e. centrally located columns. This concept is not adequate for cylindrical shells, because the tangent modulus approach pertains to idealized perfect structural members while actual structural members contain significant geometric imperfections and/or lateral loads. However, tangent modulus approach is a powerful simplified model to an actual structure in that:

- It takes account of nonlinear stress-strain behavior of the material,

- It uses linear elastic buckling analysis,

- If in-plane forces are dominating, this approach gives reasonable predictions.

\subsubsection{Geotechnical design of foundation system}

Soil parameters of the soil should be obtained by thorough investigation because the foundation design depends entirely on them. The site investigations should include a survey of sea bottom topography, site geology, geophysical investigations, in-situ determination of soil parameters by means of soundings, vane shear and cone penetration tests, and sampling in boreholes with laboratory investigations, of the samples.

\subsubsection{Pre-constructional operations}

Normally, a pre-construction phase consists of numerous known points. However, additional obstacles take contractor's attention when executing an offshore structure, generally revolving around two points:

- A geotechnical analysis of the soil,

- Seabed leveling work before placing the gravity-based structure.

Primarily, the soil on which the construction work is to be performed must undergo a careful study, then determine whether the soil is fitting to the standards required to accommodate the structure. In the case of the presence of any impurities that rupture the implementation of the project, further treatment is performed to the sand. However, in order that the process of sand treatment not to exceed its assigned budget, the depth of sand removal reaches only $10 \mathrm{~m}$, with the aid of offshore tools and ships to carry them along with labor workers, this is due to the nature of the site (Esteban, 2015; Bai, 2012).

\section{OFFSHORE GRAVITY STRUCTURES CONSTRUCTION}

\subsection{Site Selection}

It is a fact that the choice of location plays a major role in the success of the project. However, what is meant by a proper site location, here is one that will minimize the costs of transportation, along with construction assembly (Esteban, 2015).

\subsection{Facilities}

- Drydock (1st generation): The main principle that dry dock construction relies on is basically utilizing the dock as a building ground, then loading the gravitybased structures (GBS) structure by means of flooding it, as it will naturally float when the water reaches a certain height. This method is considered to be the oldest in the construction of GBS.

- Floating pontoons (2nd generation): a floating pontoon (semisubmersible barge) is used to both support the structure, and to load it to its destination, reducing the labor required to transport the structure once the construction has been finalized, and not having to dedicate site space to the construction process onshore.

- Onshore (3rd generation): creating an issue once the construction reached the final stage of loading, the construction is carried out on the docks, reinforced on the seafront. The issue here is the transportation of the reinforced structure (Sadeghi, 2001 and Esteban, 2015).

\section{STATE OF THE ART AND DISCUSSION}

Most of these new concepts are based on the F2F (floated to fixed) concept, which refers to a structure that behaves as a float during the transport phase from the port to its final location, and during the installation phase. During transport, it is necessary to have the support of small tugboats. By floating the structure, the need for vessels for transport is eliminated, except for the tugboats, thus reducing the cost of that phase. Some of these types of GBS foundations need special-purpose vessels, with the objective of transporting and installing the GBS. (Esteban, 2019).

\subsection{Crane-free gravity base (Seatower)}

The crane-free gravity base concept is a concrete structure with a relatively thin slab, an intermediate-length conical part, and a cylindrical shaft in the upper part. This concept was designed to be transported by its own flotation ability, so it is hollow inside, for which it needs the support of tugboats. It avoids the use of an expensive and weather- 
sensitive crane. This concept has been optimized for the logistics, from the manufacturing through to the decommissioning process. (Esteban, 2019).

\subsection{Gravitas gravity base (Arup/Costain/Hochtief)}

The gravitas gravity base concept is shaped similarly to the crane-free gravity base type, also having a relatively thin slab, intermediate-length cone, and cylindrical shaft in the upper part. This structure is also self-floating and can be transported to its final location only with the assistance of small tugboats.

\subsection{Strabag gravity base}

Strabag has two different gravity-base concepts. Both of them have a geometrical slab and a cylinder in the upper part. The concepts have in common joint transportation and installation of the foundation and the wind turbine generator, with preassembly being performed in port, thus reducing the number of operations carried out at sea during the installation phase. To be able to carry the floating foundation a specifically-purposed vessel is used, called Strabag carrier. Both these concepts use the pre-stressed concrete technique, they are suitable for water depths up to $\sim 45 \mathrm{~m}$, and they can be completely disassembled. (Esteban, 2019).

\subsection{GBF gravity base (Ramboll/Bmt Nigel Gee and Freyssinet)}

The GBF gravity base concept is a concrete structure with a circular slab, a conical intermediate part, and a relatively small-diameter cylinder shaft in the upper part. This concept is not self-floating and requires a specific barge for the transport and installation of the GBS structure. This specific barge is called a Transport and Installation Barge (TIB). The tower, nacelle, and rotor are assembled in the port quay before being lowered into the water. The TIB is ballasted down to the level of the base, then, upon connection, will refloat to the transportation depth. This type of foundation is suitable for water depths between 20 and $55 \mathrm{~m}$, many seabed conditions, a distance offshore between 2 and 200 miles. (Esteban, 2019).

\subsection{Rockmat and the ocean brick system (OBS)}

Rockmat is a technology for the interface between the soil and different types of support structures, such as jackets, GBS, etc. It comprises a precast base to make the entire foundation self-floating and supportable by tugboats and is installed by ballasting with water and concrete. This concept has the following advantages:

- No need for previous soil preparation,

- No costly barge crane with weather restrictions,
- With only tugboats necessary for its installation and reversible water ballasting.

Installation is estimated to be 30 hours, with the support of one 100-ton bollard-pull tugboat, three 10-ton bollardpull tugboats, and a barge to supply the concrete mixing unit and compressor.

The OBS consisting of hollow precast blocs $(10 \mathrm{~m} \times 10$ $\mathrm{m} \times 10 \mathrm{~m}$ ), piled like interconnected cubes, to create a stiff, light, strong structure. The structure can be constructed in a dry dock and floated to the site with the support of tugboats (Oumeraci, 2009).

\section{CONCLUSION}

In this paper, a special type of offshore marine structures, called the gravity platform has been described. Distinct considerations for using such a huge type of structures have been emphasized. Also, its advantages and disadvantages, as well as design requirements are described. Since for such a structure a special type of foundation is needed, so foundation preforming procedures are illustrated. Like the other structures, the construction process of this type has its own special stages, such as preconstruction, construction, maintenance after construction and operation.

Other, non-proven concepts were analyzed in this study too, some of them based on the F2F concept, which is a floating structure during the transport and installation phases, supported by small tugboats, which decreases the costs because of the self-buoyancy of the foundation and there being no need to use larger, more specific transport vessels.

\section{CONFLICT OF INTEREST STATEMENT}

The authors declare that there is no conflict of interest

\section{REFERENCES}

[1] Atkins Process Limited \& Olav Olsen A/S, (2003). Decommissioning Offshore Concrete Platforms. Health and Safety Executive.

[2] Bai, Y. \& Bai, Q. (2012). Subsea Engineering Handbook. Houston, Texas: Gulf Professional Publishing, 118-119.

[3] Chakrabarti, S. K. (2005). Handbook of Offshore Engineering. Oxford: Elsevier Ltd., 1, 19-24.

[4] Chandrasekaran, S. (2015). Dynamic Analysis and Design of Offshore Structures, Vol. 5. New Delhi: Springer, 5-7. 
[5] Esteban, M.D., Couñago, B., López-Gutiérrez, J. S., Negro, V., \& Vellisco, F. (2015). Gravity Based Support Structures for Offshore Wind Turbine Generators: Review of the Installation Process. Ocean Engineering, 110(1), 281-291.

[6] Esteban, M.D., López-Gutiérrez, J.S., \& Negro, V. (2019). Gravity Based Foundation in the Offshore Wind Sector. Journal of Marine Science and Engineering, 7(64).

[7] Hsai, Y. F. (1991). Foundation Engineering Handbook, Second Edition. New Delhi: Springer, 702-712.

[8] Nouban, F., French, R. \& Sadeghi, K. (2016). General guidance for planning, design and construction of offshore platforms. Academic Research International, 7(5), 37-44.

[9] Nouban, F., Sadeghi, K., \& Abazid, M. (2017). An overall guidance and proposition of a WBS template for construction planning of the template (Jacket) platforms. Academic Research International, 8(4), 3756.

[10] Otunyo, A.W. (2011). Design of Offshore Concrete Gravity Platforms. Nigerian Journal of Technology, 30(1), 34-46.

[11] Oumeraci, H., Pförtner, S., Kudella, M., Kortenhaus, A. (2009). Ocean Brick System (OBS) Used as a Foundation Structure for Offshore Wind Turbine. Coast, Marine Structures and Breakwater.

[12] Sadeghi, K. (2001). Coasts, Ports and Offshore Structures Engineering Book. Tehran: Power and Water University of Technology, 51-54.

[13] Sadeghi, K. (2007). An overview of design, analysis, construction and installation of offshore petroleum platforms suitable for Cyprus oil/gas fields. $G A U$ Journal of Soc. \& Applied Sciences, 2(4), 1-16.

[14] Sadeghi, K. (2007b). A numerical simulation for predicting sea waves characteristics and downtime for marine and offshore structures Installation operations. GAU Journal of Soc. \& Applied Sciences, 3(5), 1-12.

[15] Sadeghi, K. (2008). Significant Guidance for Design and Construction of Marine and Offshore Structures. Social GAU Journal and Applied Sciences, 4(7), 67-92.

[16] Tianwei, P., Yinbang, W., \& Liqin, Z. (2010). Fracture Analysis for Torsion Problems of a Gravity Platform Column with Cracks under Wind Load. Oceanic and Coastal Sea Research, 9(1), 37-42. 